\title{
ALTERATION IN RENAL FUNCTION FOLLOWING LOOP DIURETICS IN PATIENTS WITH ACUTE DECOMPENSATED HEART FAILURE
}

\author{
PRUDENCE A RODRIGUES ${ }^{1}$, SOUMYA GK ${ }^{1 *}$, NADIA GRACE BUNSHAW ${ }^{1}$, SARANYA N ${ }^{1}$, SUJITH ${ }^{1}$ \\ SHANMUGA SUNDARAM R ${ }^{2}$
}

\begin{abstract}
${ }^{1}$ Department of Pharmacy Practice, PSG College of Pharmacy, Coimbatore, Tamil Nadu, India. ${ }^{2}$ Department of Cardiology, PSG Institute of Medical Sciences and Research, Coimbatore, Tamil Nadu, India. Email: gksoumya07@gmail.com
\end{abstract}

Received: 04 September 2019, Revised and Accepted: 10 October 2019

ABSTRACT

Objective: The objective of the study was to monitor the impact of loop diuretic therapy in patients with acute decompensated heart failure (ADHF) and to assess other predictors of renal dysfunction in patients with ADHF.

Methods: An observational study over a period of 6 months from January 2018 to June 2018 in the Department of Cardiology, in a Tertiary Care Teaching Hospital, Coimbatore, Tamil Nadu. Patients on diuretic therapy (loop diuretic) were enrolled. Patients with prior chronic kidney disease were excluded from the study. The patients were evaluated based on change in serum creatinine (SCr) and other contributing factors were assessed by acute kidney injury network and worsening of renal function criteria.

Results: A total of 135 patients were enrolled, of which $73 \%$ were males and $27 \%$ were females. The mean age of the subjects was $61.55 \pm 13$ years. The baseline means SCr was $1.62 \pm 0.92 \mathrm{mg} / \mathrm{dl}$. On evaluation, $41 \%$ were really affected and $59 \%$ remain unaffected. Factors such as hypertension $(\mathrm{p}=0.047)$ and angiotensin-converting enzyme inhibitors (ACE-I) $(\mathrm{p}=0.023)$ were found to be significant predictors of renal injury.

Conclusion: Variation in renal function in ADHF patients was multifactorial. The direct influence of loop diuretics on renal function was present but was not well established. Hypertension and ACE-I have found to show influence in the development of renal injury as contributing factors. There exists both positive and negative consequence of loop diuretics on renal function.

Keywords: Acute decompensated heart failure, Loop diuretics, Renal dysfunction, Serum creatinine.

(C) 2019 The Authors. Published by Innovare Academic Sciences Pvt Ltd. This is an open access article under the CC BY license (http://creativecommons. org/licenses/by/4. 0/) DOI: http://dx.doi.org/10.22159/ajpcr.2019.v12i12.35574

\section{INTRODUCTION}

Acute decompensated heart failure (ADHF) is a clinical syndrome of new or worsening signs and symptoms of HF, often leading to prolonged hospitalization or a visit to the emergency department [1]. Patients hospitalized for ADHF often develop worsening renal function which occurs in 25-30\% [2]. Acute worsening of renal function (WRF) is one of the commonly observed clinical scenarios in $\mathrm{ADHF}$ [3]. Loop diuretics serve as a cornerstone therapy in ADHF to manage congestion [4,5]. The link between loop diuretic and renal changes is bidirectional; it can either improve or worsen renal function. Uncertainty exists about the safety and efficacy of various doses and an unknown relationship between loop diuretics and WRF [6]. Various other factors have impact on renal dysfunction, but the extent of influence of a particular factor is unknown. This study focuses on the impact of diuretics and the factors that additionally contribute to the variation in renal function.

\section{METHODS}

A prospective observational study was conducted for a period of 6 months from January 2018 to June 2018 in the department of cardiology of a tertiary care hospital, India. The study was approved by the Institutional Human Ethical Committee. All ADHF patients receiving loop diuretics were included in the study. Patients who had a prior history of chronic kidney disease were excluded from the study as it focuses on newly developed renal dysfunction. Data were collected from inpatient case sheets and hospital information system (HIS). The study population was categorized based on acute kidney injury network and WRF criteria for the analysis of factors.
Demographic variables were reported as mean \pm SD. Paired $t$-test was used to estimate the association between the baseline serum creatinine (SCr) and $\mathrm{SCr}$ at discharge.

One way ANOVA test was used to assess the association of factors like comorbidities and coadministered medications with renal function. All analysis was performed using Statistical Package for Social Sciences Version 16.0.

\section{RESULTS}

During the study period, 135 patients on loop diuretics were enrolled, of which $73 \%$ were males and $27 \%$ were females. The mean age of subjects was $61.55 \pm 13$ years (Table 1). Baseline SCr was recorded to assess the degree of renal function on admission. Based on the elevation of $\mathrm{SCr}$ from the baseline, $41 \%$ were really affected and 59\% remain unaffected. $\mathrm{SCr}$ values at the baseline and after $48 \mathrm{~h}$ of loop diuretic administration were analyzed. The mean of the baseline SCr was $1.62 \pm 0.92 \mathrm{mg} / \mathrm{dl}$ and the mean of rise in SCr after $48 \mathrm{~h}$ was $0.67 \pm 0.84 \mathrm{mg} / \mathrm{dl}$.

After the administration of loop diuretics, $41 \%$ of the population developed renal injury. The SCr levels were monitored to assess the

Table 1: Patient demographics

\begin{tabular}{lll}
\hline Demographics & $\mathbf{n = 1 3 5}(\mathbf{\% )}$ & $* \mathbf{p}$ value \\
\hline $\begin{array}{l}\text { Age (years) } \\
\text { Gender }\end{array}$ & $61.55 \pm 13$ & 0.163 \\
$\quad$ Male & $102(73)$ & 0.032 \\
$\quad$ Female & $32(27)$ & \\
\hline $\mathrm{n}=135$, Significant $p$ value $(<0.05)$ &
\end{tabular}

$\mathrm{n}=135$, *Significant $\mathrm{p}$ value $(<0.05)$. 
Table 2: Factors that influence renal dysfunction

\begin{tabular}{|c|c|c|c|c|c|c|}
\hline \multirow[t]{2}{*}{ Factors } & \multicolumn{3}{|l|}{ AKIN } & \multicolumn{3}{|l|}{ WRF } \\
\hline & AKI $(n=12) \%$ & Non-AKI $(n=20) \%$ & ${ }^{*}$ p value & WRF $(n=43) \%$ & non-WRF $(n=60) \%$ & ${ }^{*}$ p value \\
\hline \multicolumn{7}{|l|}{ Comorbidities } \\
\hline Hypertension & $7(64)$ & $4(36)$ & 0.010 & $30(48)$ & $32(52)$ & 0.045 \\
\hline Heart disease & $9(41)$ & $13(59)$ & 0.934 & $23(38)$ & $37(62)$ & 0.314 \\
\hline Anemia & $4(33)$ & $8(67)$ & 0.454 & $8(44)$ & $10(56)$ & 0.385 \\
\hline $\mathrm{rEF}<40$ & $11(46)$ & $13(54)$ & 0.352 & $22(36)$ & $39(64)$ & 0.568 \\
\hline $\mathrm{pEF}>40$ & $3(30)$ & $7(70)$ & 0.552 & $19(48)$ & $21(52)$ & 0.453 \\
\hline Pedal edema & $3(20)$ & $12(80)$ & 0.038 & $11(38)$ & $18(62)$ & 0.489 \\
\hline \multicolumn{7}{|l|}{ In-hospital medications } \\
\hline ACE-inhibitors & $11(52)$ & $10(48)$ & 0.005 & $13(30)$ & $30(70)$ & 0.030 \\
\hline ARBs & $4(100)$ & $0(0)$ & 0.010 & $4(25)$ & $12(75)$ & 0.169 \\
\hline Beta-blockers & $9(56)$ & $7(44)$ & 0.934 & $18(44)$ & $23(56)$ & 0.314 \\
\hline Metolazone & $8(31)$ & $18(69)$ & 0.643 & $4(50)$ & $4(50)$ & 0.218 \\
\hline Calcium channel blockers & $4(80)$ & $1(20)$ & 0.059 & $8(42)$ & $11(58)$ & 0.769 \\
\hline Inotropes & $2(50)$ & $2(50)$ & 0.845 & $11(55)$ & $9(45)$ & 0.561 \\
\hline
\end{tabular}

$\mathrm{n}=135,{ }^{*}$ Significant $\mathrm{p}$ value $(<0.05)$. pEF: Preserved ejection fraction, rEF: Reserved ejection fraction, ARB: Angiotensin receptor blocker, ACE: Angiotensin-converting enzyme, AKIN: Acute kidney injury network, WRF: Worsening of renal function

renal function until discharge. The decrease SCr in was observed in $76 \%$ of population which was statistically significant $(* \mathrm{p}=0.003)$. It was found that elevated $\mathrm{SCr}$ after loop diuretic administration will improve later. However, $24 \%$ of the population who developed renal injury after loop diuretic therapy had persistent elevation of SCr.

On further evaluation of the reason behind the occurrence of renal injury, it was inferred that various factors such as comorbidities and coadministered medications had an impact on renal impairment. Hypertension $(* \mathrm{p}=0.010)$ and angiotensin-converting enzyme inhibitors (ACE-I) $\left({ }^{*} \mathrm{p}=0.005\right)$ were found to have a significant impact on WRF (Table 2). This elucidated that hypertension and ACE-I are the contributing elements for renal impairment.

\section{DISCUSSION}

Over the years, renal dysfunction has been a common complication for ADHF patients. It is shown that loop diuretics have an association with worsening renal function [7]. The time to develop AKI is important, as SCr levels change at different stages of admission. During the first few days of admission for ADHF, elevation in SCr reflects cardiorenal syndrome [8], characterized by various mechanisms like renal hypoperfusion, renal venous congestion, and associated activation of cytokine and neurohormonal axes [9].

Current clinical practice exhibits a short term rise in SCr post loop diuretic therapy. It acutely causes a decrease in the estimated glomerular filtration rate (eGFR) which often leads to renal injury [10]. Worsening renal function was developed in $25-30 \%$ of the population with ADHF [2]. The cause of the incidence was unclear. In the present study, $41 \%$ of the population receiving loop diuretics developed renal impairment. Similarly, a study portrayed the use of loop diuretics was associated with a slightly greater rate of decline in eGFR [11]. Therefore, an average of $35 \%$ of patients with ADHF on loop diuretics has a possibility of developing renal injury.

Among the patients with renal dysfunction, 76\% improved at the time of discharge. It depicts that the progress of the condition was owing to the control of the disease [12]. The magnitude of dose variation among individuals was dependent on the clinical condition of the patients. Changes in the dose of diuretics were not taken into account for analysis.

The worsening picture of renal function does not merely depend on loop diuretic therapy which was similarly addressed by El-Refai et al. in a cohort study of 6071 patients, who estimated a plausible relation between day and day change in SCr with loop diuretics exposure, which denoted that loop diuretic did not have a large clinical impact on renal function [13]. However, $24 \%$ of the population who developed renal injury after loop diuretic therapy had persistent elevation of SCr. The study could not confirm that the development of renal injury was solely dependent on loop diuretics. The reason remains hypothetical, which led to the assessment of factors to figure out the correspondence.

Many studies evaluated the association of different predictors such as age, ejection fraction, comorbidities, and coadministered medications in the occurrence of AKI in ADHF patients [14-16]. The present study indicated age-related systemic effects were not correlated to the onset of renal dysfunction. ADHERE registry, an epidemiological survey showed the prevalence of hypertension serves as a risk factor for the worsening of kidney function and is approximated around 68\% [17]. The recent clinical study elaborated that hypertensive renal injury correlates most strongly with elevated pressure [18].

Correlates most strongly with elevated pressure. It was found that hypertension $(\mathrm{p}=0.01)$ was associated with renal impairment, whereas the other comorbid conditions were not statistically significant. Another study illustrated that diabetes, elevated systolic blood pressure, history of HF, tachycardia, and female gender were associated with the risk of WRF [8].

Another aspect of critical importance is regarding coprescribed medications. The impact of medications which included ACE-I, angiotensin receptor blockers (ARBs), beta-blockers, metolazone, calcium channel blockers, and inotropes was analyzed based on their potential renal effects. Well-designed clinical trials have demonstrated that ACE-I and ARBs are able to preserve renal function [19]. ACE-I had an add-on effect in renal dysfunction when combined with loop diuretics. Similar inferences were deduced from a study that describes the effect of ACE-I and ARB associated with cardiorenal risk which is likely to vary individually [20].

Therefore, disease progression along with the factors mentioned above is likely the reason for the persistence of renal injury by which loop diuretics may have its indirect effects. Furthermore, a detailed evaluation of individual patients with additional key determinants such as markers and extended sample size is required to predict the occurrence of AKI with diuretic therapy.

\section{CONCLUSION}

Variation in renal function in ADHF patients was multifactorial. The direct influence of loop diuretics on renal function was present but was not well established. Hypertension and ACE-I showed influence in the development of renal injury as contributing factors. There exists both 
positive and negative consequence of loop diuretics on renal function. Therefore, a more detailed evaluation of individual patients with additional key determinants such as markers and extended sample size is required to assess the WRF.

\section{ACKNOWLEDGMENT}

We express our heartfelt gratitude to the Ethics Committee of PSG Hospitals. We thank Dr. Sivakumar V, Associate Professor, and Department of Pharmacy Practice PSG College of Pharmacy for his kind support. We thank our fellow mates Nitya Suresh and Ramya M, for their peer support. There are no other conflicts of interest.

\section{AUTHORS' CONTRIBUTIONS}

All the authors have contributed equally to the design, development, review, and finalization of the contents of the manuscript.

\section{CONFLICTS OF INTEREST}

The authors declare that there are no conflicts of interest regarding the publication of this paper.

\section{REFERENCES}

1. Meyer TE. Approach to Acute Decompensated Heart Failure in Adults. Waltham, MA: UpToDate; 2019.

2. Han SW, Ryu KH. Renal dysfunction in acute heart failure. Korean Circ J 2011;41:565-74.

3. Shirakabe A, Hata N, Kobayashi N, Shinada T, Tomita K, Tsurumi M, et al. Prognostic impact of acute kidney injury in patients with acute decompensated heart failure. Circ J 2013;77:687-96.

4. Damman K, Navis G, Smilde TD, Voors AA, van der Bij W, van Veldhuisen DJ, et al. Decreased cardiac output, venous congestion and the association with renal impairment in patients with cardiac dysfunction. Eur J Heart Fail 2007;9:872-8.

5. Felker GM, Lee KL, Bull DA, Redfield MM, Stevenson LW, Goldsmith SR, et al. Diuretic strategies in patients with acute decompensated heart failure. N Engl J Med 2011;364:797-805.

6. Felker GM, O'Connor CM, Braunwald E, Heart Failure Clinical Research Network Investigators. Loop diuretics in acute decompensated heart failure: Necessary? Evil? A necessary evil? Circ Heart Fail 2009;2:56-62.

7. Peacock WF, Costanzo MR, De Marco T, Lopatin M, Wynne J, Mills RM, et al. Impact of intravenous loop diuretics on outcomes of patients hospitalized with acute decompensated heart failure: Insights from the ADHERE registry. Cardiology 2009;113:12-9.

8. Krumholz HM, Chen YT, Vaccarino V, Wang Y, Radford MJ, Bradford WD, et al. Correlates and impact on outcomes of worsening renal function in patients and gt; or $=65$ years of age with heart failure. Am J Cardiol 2000;85:1110-3.

9. Roy AK, Mc Gorrian C, Treacy C, Kavanaugh E, Brennan A, Mahon NG, et al. A comparison of traditional and novel definitions (RIFLE, AKIN, and KDIGO) of acute kidney injury for the prediction of outcomes in acute decompensated heart failure. Cardiorenal Med 2013;3:26-37

10. Kalra OP, Aggarwal A. Rational use of diuretics and pathophysiology of edema. Medicine 2012;22:601-10.

11. Damman K, Kjekshus J, Wikstrand J, Cleland JG, Komajda M, Wedel H, et al. Loop diuretics, renal function and clinical outcome in patients with heart failure and reduced ejection fraction. Eur J Heart Fail 2016;18:328-36.

12. Onuigbo MAC, Agbasi N, Sengodan M, Rosario KF. Acute kidney injury in heart failure revisited-the ameliorating impact of "Decongestive diuresis" on renal dysfunction in Type 1 acute cardiorenal syndrome: Accelerated rising pro B naturetic peptide is a predictor of good renal prognosis. J Clin Med 2017;6:E82.

13. El-Refai M, Krivospitskaya O, Peterson EL, Wells K, Williams LK, Lanfear DE, et al. Relationship of loop diuretic dosing and acute changes in renal function during hospitalization for heart failure. J Clin Exp Cardiolog 2011;2:1000164.

14. Damman K, Valente MA, Voors AA, O'Connor CM, van Veldhuisen DJ, Hillege HL, et al. Renal impairment, worsening renal function, and outcome in patients with heart failure: An updated meta-analysis. Eur Heart J 2014;35:455-69.

15. Al-Naher A, Wright D, Devonald MAJ, Pirmohamed M. Renal function monitoring in heart failure what is the optimal frequency? A narrative review. Br J Clin Pharmacol 2018;84:5-17.

16. Metra M, Nodari S, Parrinello G, Bordonali T, Bugatti S, Danesi R, et al. Worsening renal function in patients hospitalised for acute heart failure: Clinical implications and prognostic significance. Eur J Heart Fail 2008;10:188-95

17. Ahmed A, Campbell RC. Epidemiology of chronic kidney disease in heart failure. Heart Fail Clin 2008;4:387-99.

18. Sanjay K, Surendra H. An elevated pulse pressure: A major risk factor for cardiovascular diseases. Int J Pharm Pharm Sci 2013;5:5-11.

19. Mohd M, Normi H. Effect of angiotensin converting enzyme inhibitors and angiotensin-ii receptor blockers on proteinuria of hypertensive patients in standard care practice. Int J Pharm Pharm Sci 2015;11:40-3.

20. Schmidt M, Mansfield KE, Bhaskaran K, Nitsch D, Sørensen HT, Smeeth $\mathrm{L}$, et al. Serum creatinine elevation after renin-angiotensin system blockade and long term cardiorenal risks: Cohort study. BMJ 2017;356:j791. 